\title{
12
}

\section{The Fraught Dichotomy between Context and Tendency Evidence in Sexual Assault Cases - Suggestions for Reform}

\author{
John Anderson ${ }^{1}$
}

These distinctions [between tendency and relationship/context evidence] - somewhat fine - are productive of much uncertainty, and therefore much difficulty for trial judges. In a trial for a sexual offence, where many of these concepts may intersect, the task of a trial judge in explaining coherently the use (and non-misuse) of evidence falling within the different categories is an unenviable one, as is the task of a jury of lay persons in comprehending and faithfully applying the required directions. In my opinion, relationship evidence - including context evidence - should be seen for what it is. It is tendency evidence. ${ }^{2}$ 


\section{Background: Characterisation of Evidence as Tendency or Relationship/Context}

Evidence to establish a relationship between the defendant and complainant in a trial involving allegations of sexual assault or to provide a contextual background to those allegations has been held to be relevant for a variety of reasons, ${ }^{3}$ although they can be summed up as going to the credibility of the complainant by assisting to explain what the tribunal of fact often perceives to be their counterintuitive behaviours. Relevance will depend on the nature of the defence case, as relationship evidence can place the complainant's account of events in its realistic context, thus providing the capacity to answer questions which 'may fairly be expected to arise in the minds of the jury were they limited to a consideration of evidence of the offences charged'. ${ }^{4}$ Accordingly, on those bases such evidence will ordinarily reach the threshold of a minimal logical connection to 'the probability of the existence of a fact in issue in the proceeding, ${ }^{5}$ usually whether the sexual conduct took place at all. As Howie J usefully observed, it is evidence that 'may allow the jury to infer some aspect of the complainant's conduct but it does not give rise to any inference about the accused's conduct'. ${ }^{6}$

Importantly, context evidence cannot be used for a tendency purpose, that is, to establish that any of the charged offences occurred or as tending to show the defendant had wrongful sexual feelings towards the complainant and it was more likely they committed those offences. ${ }^{7}$ In practice, the nature of context evidence is finely distinguished from tendency evidence particularly where it involves uncharged sexual acts of the same general nature as the sexual assault charges in the indictment. There is clear potential for overlap, which results in significant complexity in properly categorising the evidence. Priest JA was driven to the conclusion that 'relationship evidence - including context evidence - should be seen for

3 For example, it may be relevant to explain why a complainant feared the defendant $(R v A H$ (1997) 42 NSWLR 702; $R v$ WJT [2001] NSWCCA 405), or why there was a failure to show distress or complain: KTR $v$ The Queen [2010] NSWCCA 271, [99]-[101]; FH $v$ The Queen [2014] NSWCCA 231, [49]-[50].

4 HML $v$ The Queen (2008) 235 CLR 334, 397 (Kiefel J). See also Steadman $v$ The Queen (No 2) [2013] NSWCCA 56, [13].

5 Evidence Act 1995 (Cth) s 55. The Evidence Acts in NSW, Victoria, Tasmania, ACT and NT are modelled on the Commonwealth Act and are substantially uniform in their construction.

6 Qualtieri v The Queen (2006) 171 A Crim R 463, 494.

7 Rodden $v$ The Queen [2008] NSWCCA 53, [48]. 
what it is ... tendency evidence'. ${ }^{8}$ Although the other two judges didn't join in this opinion, ${ }^{9}$ the correct characterisation of the 'true relevance' of the evidence is a most important concern of the courts as they must ensure that relationship evidence is not simply 'tendency evidence admitted by the back door'. ${ }^{10}$ In the interests of a fair trial, the existence of this complex dichotomy is such that the court must either exclude relationship/context evidence entirely or properly limit its use through precise guidance. Specific examples of evidence that may not be admissible if relationship/context evidence was treated as if it were tendency evidence include: multiple huggings by an adult of a child by bringing their whole bodies into contact for an extended period, ${ }^{11}$ being very 'touchy feely' with a young child by having an arm constantly around her and kissing her on the cheek, ${ }^{12}$ and multiple acts of a sexual nature such as being naked and masturbating in the presence of a child, walking in while the child is showering, trying to get into the child's bed and demanding she take off her clothes. ${ }^{13}$

There are important procedural distinctions in the admissibility of these two subtly different types of evidence. Relationship/context evidence doesn't fall within the s 97 exclusionary rule or the further admissibility restriction in s 101(2). After meeting the relevance threshold, it becomes subject only to judicial exclusion through ss 135 or 137 . As such evidence is invariably adduced by the prosecution in sexual assault cases, the defendant seeking exclusion under $s 137$ must persuade ${ }^{14}$ the court that the 'probative value ${ }^{15}$ is outweighed by the danger of unfair prejudice to the defendant'. ${ }^{16}$ This onus is directly opposed to ss 97 and 101(2) which makes tendency evidence inadmissible unless the prosecution

8 Murdoch $v$ The Queen, above $\mathrm{n} 2$.

9 Observing at [11] it was 'not the occasion ... to explore context or relationship evidence' in the specific circumstances of the case.

10 RWC $v$ The Queen [2010] NSWCCA 332, [115]; Steadman $v$ The Queen (No 2) [2013] NSWCCA 56, [11]-[18].

11 See $R v$ Landmeter [2015] SASCFC 3.

12 See $R v$ Zappavigna [2015] SASCFC 8.

13 Steadman $v$ The Queen [No 1] [2013] NSWCCA 55 and Steadman v The Queen [No 2] [2013] NSWCCA 56.

$14 R v D G$ [2010] VSCA 173, [54].

15 Probative value is taken 'at its highest': see IMMv The Queen [2016] HCA 14, [44]-[58].

16 That is, a real risk that the evidence will be misused in some unfair way: see $R v$ Lisoff [1999] NSWCCA 364. 
persuades the court that the evidence is of 'significant probative value' ${ }^{\text {' }}$ and it substantially outweighs any prejudicial effect it may have on the defendant.

Therefore, rather than relationship/context evidence being excluded under s 137, it is often admitted as relevant subject to the need for careful judicial directions about its limited use in jury deliberations, particularly that 'the relationship evidence cannot be regarded as a substitute for the evidence that the accused committed the charged sexual acts, or for the purpose of showing that the accused is "the kind of person" likely to have committed that offence'. ${ }^{18}$ As Priest JA observed, this is an 'unenviable task', ${ }^{19}$ which assumes juror comprehension of using the evidence for a purpose that has been otherwise described as 'contrary to ordinary human experience ${ }^{20}$ and counterintuitive to the ordinary reasoning processes of lay fact-finders about human behaviour. The directions are supposed to be capable of ameliorating the potential prejudicial effect to the defendant; however, various jury studies indicate the assumption of courts that directions are effective may be misplaced in certain circumstances. ${ }^{21}$

17 The divergent Victorian and NSW judicial approaches to the interpretation of the phrase 'significant probative value' in s 97 evident when comparing Velkoski $v$ The Queen [2014] VSCA 121 with Hughes $v$ The Queen [2015] NSWCCA 330 were resolved by a 4:3 majority decision of the High Court in Hughes v The Queen [2017] HCA 20. The broader NSW approach was adopted by the High Court in holding that similarity between the tendency evidence and facts in issue of the charged offence is not a pre-requisite to a finding of 'significant probative value'. The tendency evidence should make more likely, to a significant extent, the facts that make up the elements of the offence charged either by itself or together with other evidence adduced or to be adduced in the case. This does not include a requirement for "similarity or ... of "underlying unity", "pattern of conduct" or "modus operandi"'(per Keifel CJ, Bell, Keane and Edelman JJ at [34]).

18 Benson $v$ The Queen [2014] VSCA 51, [30] (Neave JA).

19 Murdoch $v$ The Queen, above $\mathrm{n} 2$.

20 DJV v The Queen [2008] NSWCCA 272, [31]. See also Qualtieri v The Queen (2006) $171 \mathrm{~A}$ Crim R 463 where the court referred to the NSW Judicial Commission Criminal Trial Courts Bench Book model direction on relationship evidence ([4-215]) with approval.

21 See, for example, Wissler and Saks, 'On the Inefficacy of Limiting Instructions' (1985) 9 Law and Human Behaviour 37; Lloyd-Bostock, 'The Effects on Juries of Hearing about the Defendant's Previous Criminal Record: A Simulation Study' (2000) Criminal Law Review 734; Schaefer and Hansen, 'Similar Fact Evidence and Limited Use Instructions: An Empirical Investigation' (1990) 14 Criminal Law Journal 157; Cush and Goodman-Delahunty, 'The Influence of Limiting Instructions on Processing and Judgments of Emotionally Evocative Evidence' (2006) 13(1) Psychiatry, Psychology and Law 110. Compare Trimboli, 'Juror Understanding of Judicial Instructions in Criminal Trials' (2008) NSW BOCSAR Crime and Justice Bulletin No 119. 


\section{The Problem}

The upshot of experiences in criminal trials and appeals involving sexual assault offences is a fraught dichotomy between relationship/context and tendency evidence. The essential problem is whether priority should be given to admitting all probative evidence or to minimising the risk of wrongful convictions.

Policy arguments to accommodate admissibility of relationship/context evidence focus on facilitating the successful prosecution of sexual assault charges, particularly cases where the perceived counterintuitive behaviours revealed in testimony requiring some form of explanation may be most evident. Arguments include that the entire law enforcement and court process makes it difficult for complainants, particularly children, to be encouraged to report sexual assaults and then give evidence in court, the low rate of convictions where such cases proceed to trial, and the serious nature of the problem in society where it is perceived as abhorrent but that most perpetrators 'get away with it'. The arguments for more liberal admissibility of 'discreditable' forms of evidence extend to lowering the threshold of admissibility of tendency evidence because of courts 'placing unwarranted obstacles in the path of efforts to prosecute child sexual offenders. ${ }^{22}$ The trial spotlight is on the 'battle of credibility between the complainant and the defendant' where the presumption of innocence and the standard of proof beyond reasonable doubt are viewed as strongly favouring the defendant such that the stringent operation of the exclusionary rule is challenged and it is contended that other probative misconduct evidence should be more readily admissible. ${ }^{23}$

Contrary to these arguments, the overriding requirement of a fair trial for a defendant who is presumed innocent and the highly prejudicial nature of most relationship/context evidence, particularly uncharged sexual acts, raises counter-arguments that there must be closer analysis of the relevance of context evidence and a transparent balancing of the important factors in deciding its admissibility to ensure a conviction is not on the basis of suspicion and unfair preconceptions of a defendant's

22 Hamer, 'Proof of Serial Child Sexual Abuse: Case-law Developments and Recidivism Data' in Crofts and Loughnan (eds), Criminalisation and Criminal Responsibility in Australia (2015), 247, 250-51. See also Cossins, "The Behaviour of Serial Child Sex Offenders; Implications for the Prosecution of Child Sex Offences in Joint Trials' (2011) 35(3) Melbourne University Law Review 821.

23 Hamer, above n 22, 244, 260. 
'character'. The frequency and likeness of the 'discreditable' conduct can ultimately lead to a blurring of the incidents and preemptive judgment of guilt without the ordinary procedural safeguards that apply to proof of a criminal offence. That does not necessarily mean there will be fewer convictions in these cases; rather, due process and fairness are placed at the forefront of procedural and evidentiary considerations.

\section{Suggestions for Reform}

The Australian Law Reform Commission (ALRC) considered a proposal for broadening the scope of $s 101$ to encompass all evidence that tends to reveal the past disreputable conduct of a defendant. ${ }^{24}$ There were strongly opposing views: concern that such dangerous evidence was currently too readily admitted into evidence against the concern that important probative evidence would be excluded leading to inconsistent outcomes. ${ }^{25}$ The three procedural safeguards which apply to tendency evidence in relation to the party bearing the onus of proof, the heightened barrier for admissibility requiring significant probative value, and the evidence having 'any prejudicial effect' as opposed to a 'danger of unfair prejudice' were examined for extension to context evidence. Ultimately, though, the ALRC view was that the prosecution would be likely in practice to 'disavow any attempt to use the evidence for a propensity purpose and concede the need for a warning that the evidence not be used for that purpose $^{26}$ thereby providing a strong argument that the probative value for a context purpose substantially outweighs any prejudicial effect on the defendant. This approach takes advantage of the court's firm assumption that limiting directions are capable of alleviating prejudice, making it difficult for the defence to challenge admissibility on the basis that directions would be inadequate. Overall, the benefits were found to be inconclusive and, as extending the scope of s 101 was unlikely to have a practical impact, it was better not to do so. This reasoning was largely speculative and not persuasive.

24 Australian Law Reform Commission (ALRC), Uniform Evidence Law, Report 102 (2005), [11.76].

25 Ibid. [11.80]-[11.81].

26 Ibid. [11.87]. 
South Australia, a common law jurisdiction, inserted s 34P into their Evidence Act $1929,{ }^{27}$ which makes evidence of all 'discreditable conduct', including uncharged sexual acts, presumptively inadmissible. The prosecution must persuade the judge that the probative value of such evidence, which relies on a particular disposition of the defendant as circumstantial evidence of a fact in issue, is strong having regard to the particular issue/s arising at trial and must substantially outweigh any prejudicial effect it may have on the defendant before it is admissible. When determining the balance between probative value and prejudicial effect the judge must consider whether the permissible use of the discreditable conduct evidence can be kept sufficiently separate and distinct so as to remove any appreciable risk of it being used impermissibly to prove that the defendant is more likely to have committed the offence. The legislative intention is to ensure that the trial judge engages in a transparent balancing task to reflect the more burdensome threshold for admissibility of this potentially dangerous evidence. Further, s $34 \mathrm{R}$ requires the trial judge to identify and explain to the jury the purposes for which the discreditable conduct evidence may and may not be used. This is to compel judges to carefully consider the nature and utility of directions. The genuine effectiveness of such directions is not directly addressed by the legislation and can only be urged in defence arguments using relevant studies and empirical evidence.

The practical effect of these provisions can be gauged through their interpretation and application in the cases. Largely, the ALRC prediction in relation to extending the scope of $s 101$ has been realised through the practical operation of s 34P. Judges continue to rely heavily on the utility of directions to ameliorate the prejudicial effect of relationship/ context evidence and have continued to admit such evidence as relevant and probative ${ }^{28}$ or have characterised it as forming part of the proof of elements of generalised charges, such as 'persistent sexual exploitation of a child'. ${ }^{29}$ If the courts continue to make the assumption that directions are effective in restricting prejudice, the legislative efforts through the transparent balancing test with the prosecution onus to persuade the

27 Evidence (Discreditable Conduct) Amendment Act 2011 (SA) commenced 1 June 2012. An important catalyst was the confusing aftermath of the High Court decision in HML $v$ The Queen (2008) 235 CLR 334.

28 See, for example, $R v$ Maiolo (No 2) (2013) 117 SASR 1; $R v C, C N$ [2013] SASCFC 44; $R v$ Zappavigna [2015] SASCFC 8, [34]-[60]; $R v F$, AD [2015] SASCFC 130, [21]-[41].

29 See $R v$ Landmeter [2015] SASCFC 3, [27] (Vanstone and Bampton JJ), [113]-[114] (Peek J dissenting). 
court that the 'discreditable evidence' should be admitted will come to nought. Arguably the intent and spirit of the legislation would support a more exacting application of the admissibility threshold with directions only available where they can effectively remove any appreciable risk of the evidence being used for the impermissible purpose.

If it is largely about maintaining the credibility of complainants because they appear to have behaved in a counterintuitive manner, then more liberal use of expert evidence to explain this behaviour may be preferable to the possibility of creating another statutory exclusionary rule. Alternatively, these reforms could operate to complement each other in practical operation and effect. The credibility of a complainant may be tainted to varying degrees by having to narrate isolated incidents, as the jury may find such a disjointed account to be 'astonishing, and almost unbelievable'. ${ }^{30}$ This reform suggestion raises the issue of whether expert evidence is an effective and less prejudicial alternative to the use of relationship/context evidence as a means of dispelling common misconceptions about how sexual assault complainants behave, both before and after sexual abuse, particularly where it has been systematic and sustained.

Sections 79(2) and 108C(2) specifically provide for the use of expert evidence in child sexual assault cases, allowing persons with specialised knowledge to testify on matters concerning child development and behaviour as an exception to the opinion and credibility rules. ${ }^{31}$ In $M A v$ The Queen the prosecution led expert evidence at trial 'with respect to the behavioural framework within which the evidence of the complainant's reactions to the alleged abuse should be assessed and understood'. On appeal this was argued to be irrelevant and unfairly prejudicial, but the Court of Appeal ruled it was relevant and not so unfairly prejudicial that exclusion was warranted as it 'could establish that the counterintuitive behaviour complained of was of neutral significance ... [and] could not demonstrate that the behaviour rendered it more or less likely that offending had occurred as alleged'. ${ }^{32}$ This case deals with the very situation contemplated by legislators and shows its successful use in practice to explain the counterintuitive behaviours of a complainant in a

$30 \quad R v$ Beserick (1993) 30 NSWLR 510, 515.

31 These provisions commenced 1 January 2009 to curb the judicial reluctance to allow such expert evidence because it wasn't considered to be outside the ordinary experience of jurors - ALRC, above n 24, [9.156].

32 (2013) 226 A Crim R 575, [22]-[34]. 
child sexual assault case. Overall, though, prosecutors don't appear to have regularly invoked these provisions to evidence that psychological research doesn't support many of the existing misconceptions. ${ }^{33}$

One concern is the 'white coat effect': that undue weight will be given to this evidence because of the aura of scientific certainty surrounding expert testimony. ${ }^{34}$ Therefore, it is important to situate the role of this evidence and consider directions about its use. The court is 'simply offered an alternative explanation for specific behaviour', without being offered an opinion on the specific credibility of the complainant, so the jury is assisted not supplanted by the expert. ${ }^{35}$ Arguably an increased use of expert testimony in sexual assault cases would reduce the need for a complainant to recount a history of 'grooming' conduct by a defendant. This approach won't be successful for all forms of relationship/context evidence but it may represent a more objective way of maintaining the complainant's credibility without causing undue prejudice to the defendant. To obviate appeals about judicial directions it is contended that a standardised direction about psychological research into child development and behaviour during and following sexual abuse should be developed. This could be incorporated into legislation ${ }^{36}$ and Law Reform Commissions have recommended the development of model directions drawing on the expertise of relevant professional and research bodies. ${ }^{37}$

\section{Conclusion}

The dichotomy between tendency and relationship/context evidence in sexual assault cases cannot be logically sustained when the real relevance of relationship/context evidence is realised. First, given the prejudicial nature of most relationship/context evidence, it should be presumptively

33 Arguably such experts are material witnesses and should be called by the prosecution: $R v$ Apostilides (1984) 154 CLR 563. These provisions may also be used by the defence so there may be prosecutorial reluctance based on an expectation that the defence will counter with expert evidence to reinstate the misconceptions. Experience in practice, however, shows that such defence tactics are likely to meet with judicial resistance: see $R v W R$ (No 3) [2010] ACTSC 89, [32].

34 Ward, 'Usurping the Role of the Jury? Expert Evidence and Witness Credibility in English Trials' (2009) 13 International Journal of Evidence and Proof 83, 88.

35 Ellison, 'Closing the Credibility Gap: The Prosecutorial Use of Expert Witness Testimony in Sexual Assault Cases' (2005) 9 International Journal of Evidence and Proof 239, 258.

36 See Jury Directions Act 2015 (Vic) ss 27, 29; and Evidence Regulation 2007 (NZ) cl 49.

37 Cossins for the National Child Sexual Assault Reform Committee, 'Alternative Models for Prosecuting Child Sex Offences in Australia' (2010), 233-35; ALRC, Family Violence, Report 114 (2009) [27-11]-[27-12]; NSW Law Reform Commission, Jury Directions, Report 136 (2012) [5.5]. 
inadmissible. The prosecution must persuade the court it is admissible through a transparent balancing of probative value and prejudicial effect. Judges must not simply rely on the outmoded notion that jury directions will ameliorate any prejudice to defendants. Second, the courts should move towards increased use of expert evidence to explain counterintuitive behaviours of complainants so that the prosecution can still present its case fairly and thoroughly but with decreased reliance on highly prejudicial relationship/context evidence. 
This text is taken from New Directions for Law in Australia: Essays in Contemporary Law Reform, edited by Ron Levy, Molly O’Brien, Simon Rice, Pauline Ridge and Margaret Thornton, published 2017 by ANU Press, The Australian National University, Canberra, Australia. 